\title{
SOME NOTES ON THE RAPID ELECTRO-DEPOSITION OF COPPER.
}

\author{
By SHERARD COWPER-COLES.
}

\begin{abstract}
(A Paper read before the Faraday Socicty on Monday, Fuly 3, 1905,
\end{abstract} Mr. W. R. Cooper in the Chair.)

\section{SYNOPSIS.}

Comparison of current densities used in various electrolytic refineries. Description of different methods for increasing the rate of deposit. (a) Revolving or moving the cathode. (b) Burnishing the copper during deposition. (c) Insulating the excrescences or growths to prevent further increase. $(d)$ Rapid circulation of the electrolyte. (e) Revolving the cathode at a critical speed. Method employed for determining the critical speed. Effect of the centrifugal action. Purity of copper produced in impure solutions. Composition of the electrolyte. Increase of strength due to increased speed. Lamination caused by variation of speed. Growth and formation of trees and nodules. Wave lines obtained with vertical revolving cathodes. Curve showing voltage required for rotating cathodes driven at critical speed. Description of plant required for centrifugal process. Application to wire manufacture. Cost of working. Advantages claimed for process. Conclusion.

It has been the aim of electrometallurgists, ever since copper-refining was introduced by Messrs. Elkington in the year I869, to increase the rate at which the copper can be deposited in a smooth form without any large increase in the voltage. The current density employed in electrolytic refineries has been gradually increased from about 8 or io amperes, as employed by Messrs. Elkington's and Elliott's at Birmingham, to 20 amperes per sq. $\mathrm{ft}$. as at present employed at the Anaconda works; the current density will, no doubt, be further increased in electrolytic refining plants in the near future.

It has been argued by several writers that 16 or I7 amperes per sq. $\mathrm{ft}$. is the economical limit, and that beyond this limit an increase of current density means an increased expenditure in fucl, but these writers make no adequate allowance for the saving effected by the more rapid treatment of the copper, and consequently the greatly reduced amount of copper under treatment and the interest on capital expenditure that is saved. The table on p. 217 gives comparative data of current density employed at various copperrefining works, compiled from Ulke's book on Electrolytic Copper Refining.

Various attempts have been made from time to time to further increase the current density by using mechanical means for keeping the copper from getting rough by rubbing down or smoothing the raised portions. The various processes for accomplishing this end may be classified under frve headings :- 
I. Revolving or moving the cathode.

2. Burnishing the copper during deposition.

3. Insulating the excrescences or growths on the copper, so as to prevent further increase.

4. Rapid circulation of the electrolyte.

5. Revolving the cathode at a critical speed (centrifugal process).

Under Class I may be mentioned the process of Wilde, which has for its object the deposition of copper on iron rolls for printing purposes, and patented in the year 1875 . Illustration I represents the apparatus employed; the cathode is revolved slowly, the anodes being made from copper tubes. In this way an even thickness of deposit is obtained over the whole surface; uniform along the length of the roller, by reason of the motion imparted to the solution, which maintains an equal density of solution throughout; and uniform as to its diameter, because the rotation constantly brings fresh surfaces opposite the anodes. Additional means for securing a thorough mixture is employed by attaching a small propeller blade to a shaft run by the same machinery that actuates the cathodes. The object of rotating the cathode is to help keep the electrolyte circulated, and to ensure an even corrosion of the anode, and an even deposit of copper on the cathode. The relative position of the cathode and the anode is altered from time to time by giving the nuts holding the anodes a fraction of a turn. The current density employed is comparatively low; the operation requires many days. Illustrations 2 and 3 show Cotsworth's apparatus, and Illustration 4 Wylie's and Grant's ; the former is very similar to Wilde's apparatus, the chief difference in the latter being that both anode and cathode are rotated; the apparatus consists of a vertical central rotating anode $\mathrm{C}$, the iron rollers to be coated $(B)$ rotate on their own axes by means of the gearing shown in the illustration, and are also caused to revolve around the central anode.

Class 2.-Burnishing the copper during electro-deposition is the process employed at the factories worked under the Elmore process; the burnishers are of agate, the mechanical arrangement for operating them is shown in Illustration 5, the usual current density being under 20 per square foot, and the voltage at the electrodes from $0_{5} 5$ to $\mathrm{I}$ volt; a 4 -in. mandrel is revolved at about 30 revolutions per minute.

Class 3.-Insulating the excrescences or growths on the deposited tubes is the process in which a sheepskin burnisher is substituted for an agate one, smooth deposits being obtained by the application of an insulating coating to the inequalities on the surface. The sheepskin impregnators, which move over the surface of the metal, coat all projecting parts with a thin film of animal fat, which hinders further deposition until the surrounding depressions have been raised to the common level. In later patents impregnators are mentioned composed of organic, gelatinous, or albuminous matter, free from excess of grease, rendered insoluble by treatment with bichromate, or the softening of the albuminous or gelatinous constituents of the impregnators is prevented by soaking them with a solution of formic aldehyde. It is claimed for impregnators so treated that they may be employed with equal facility in a hot or cold bath. The current used is from 35 to 40 amperes per square foot of cathode area, the voltage required is about $\mathrm{I} \cdot 6$ per vat. Tubes are deposited $\mathrm{I} 2 \mathrm{ft}$. in length and $\mathrm{I} 6 \mathrm{in}$. diameter and $\frac{1}{8}$ in. thick ; these are longitudinally cut, and opened to form sheets.

Illustrations 6 and 7 show the construction of the apparatus, the mandrel is revolved in a horizontal position, and about two-thirds of it is immersed in the electrolyte, and the sheepskin burnisher, A, is caused to travel the whole length of the mandrel by means of the mechanism shown in the illustration. 
ELECTRO-DEPOSITION OF COPPER

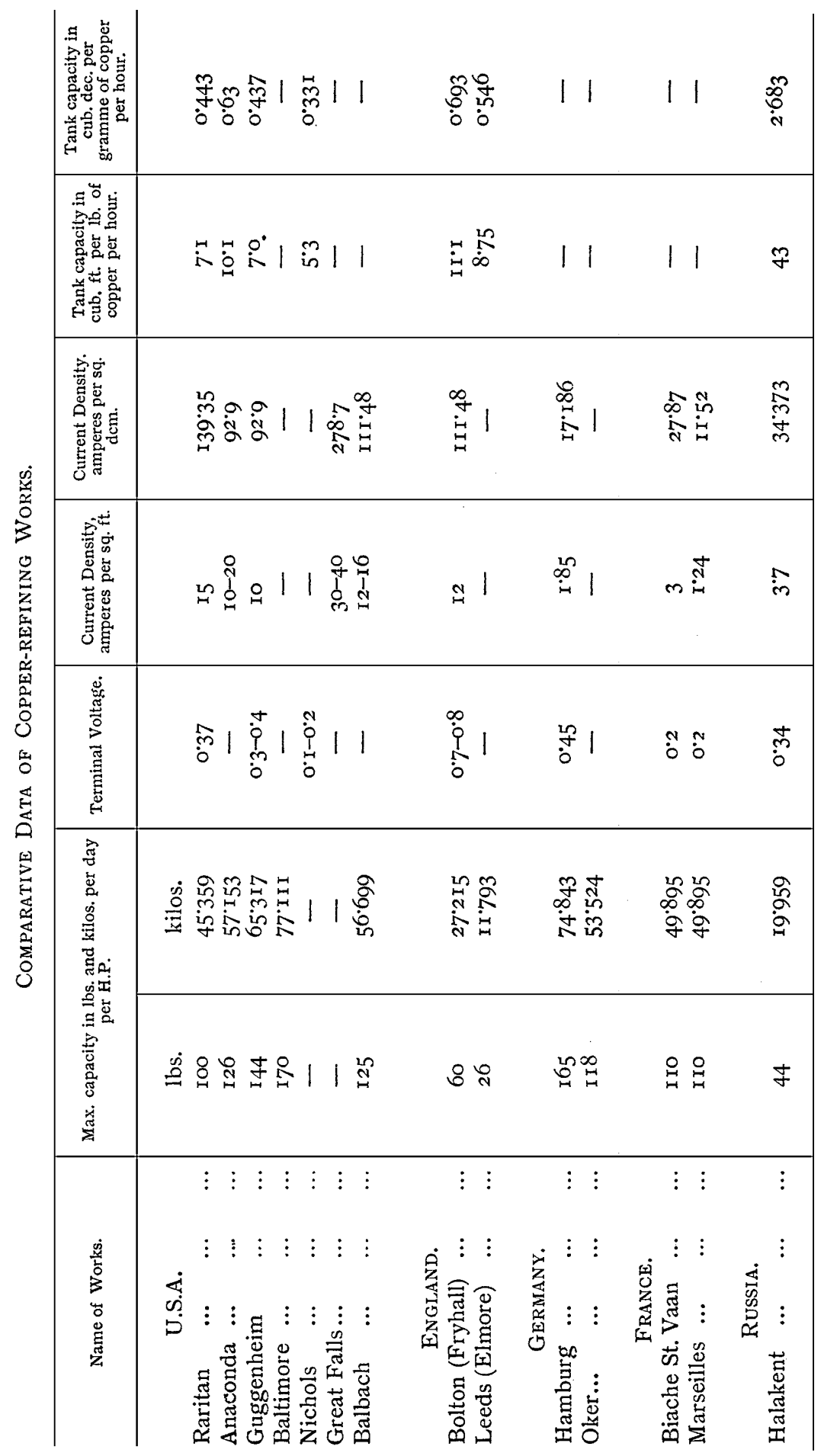


It was found that if a fixed path of reciprocation be followed by the membranes or burnishers, at the points where the reversal of motion takes place, rings are produced upon the cathode. To overcome this defect the point of reversal is gradually shifted, first to the right and then to the left, by means of a suitable worm-wheel and gearing. B and C are perforated plates, which are shaped to the contour of the cathode, and between which the anode metal is placed.

Class 4.-Rapid Circulation of the Electrolyte.-Electrometallurgists have known for a considerable time that the rate of electrodeposition can be greatly increased by rapidly circulating the electrolyte or by impinging or injecting the electrolyte against the cathode. One distinct advantage in the use of the jets is obviously to be found in the certainty that the electrolyte at the surface of the cathode is constantly and thoroughly renewed, so that a much greater current density may be employed than would otherwise be possible, and it has the advantage over processes using a mechanical burnisher that there is not the same tendency for the copper to be deposited in layers. Swan has experimented with impinging jets on revolving cathodes, and Elmore in the year 1886 took out a patent, in which he describes a process for depositing copper on revolving discs, the copper being consolidated by means of burnishers, and the electrolytic liquid forced against the surfaces of the cathodes so as to remove bubbles of gas, perforated pipes being provided for the purpose between the cathodes.

Thofehrn in 1893 introduced a method of depositing copper under the influence of impinging jets. The copper was deposited upon a long hollow cylindrical cathode, $8 \mathrm{ft}$. (2.44 metres) long, and $3 \mathrm{ft}$. (9r.44 cm.) in diameter, which was immersed in the electrolyte, and revolved at a low speed, whilst the copper was deposited upon it with a current density of 50 to roo amperes per square foot $\left(9^{2} 29 \mathrm{sq}\right.$. $\mathrm{dcm}$.). During the time of depositing, numerous jets of the electrolyte were caused to play under pressure upon the surface of the cylinder; see Illustration No. 8, Figs. I and 2, which illustrate his system of depositing copper on revolving cathodes, and Figs. 3 and 4 on stationary cathodes, the anodes being common converter pig, shot, or scrap copper. It was claimed for this process that the crystals of copper were deposited in the form of microscopic octagonal hair-like filaments, which become felted and compressed by the jets of liquid; and that the cylinders of copper, when they had been deposited an inch thick and been detached from the cathode cylinders, could be rolled direct. It has also been claimed that the wires produced by this process were over I $_{5}$ per cent. stronger than those prepared by the old electrolytic refining process, followed by casting, rolling, and drawing, and that the expense of such an electric refining of the metal to produce the bars required for the rolling or wire-drawing mill was $\$ 16$ ( $f_{3} 36 \mathrm{~s}$.) per ton. It is generally understood that this process, which was tried by the Anaconda Copper Refining Company, has been abandoned.

Graham patented an apparatus in 1896 , in which the electrolyte is discharged on to flat cathode surface by means of jets, preferably from circular orifices, but when depositing on a cylinder the jets take the form of slits at right angles to the axle of the cylinder. The copper anodes, which have surfaces eight or nine times greater than that upon which the deposit is to take place, are in a spiral, gridlike, or corrugated form. The edges of the cathode are in all cases protected by a shield of vulcanite to prevent irregular deposits on the edges. According to his specification, a nearly saturated solution of copper sulphate, containing $5 \mathrm{oz}$. (I4I.75 grms.) of strong sulphuric 


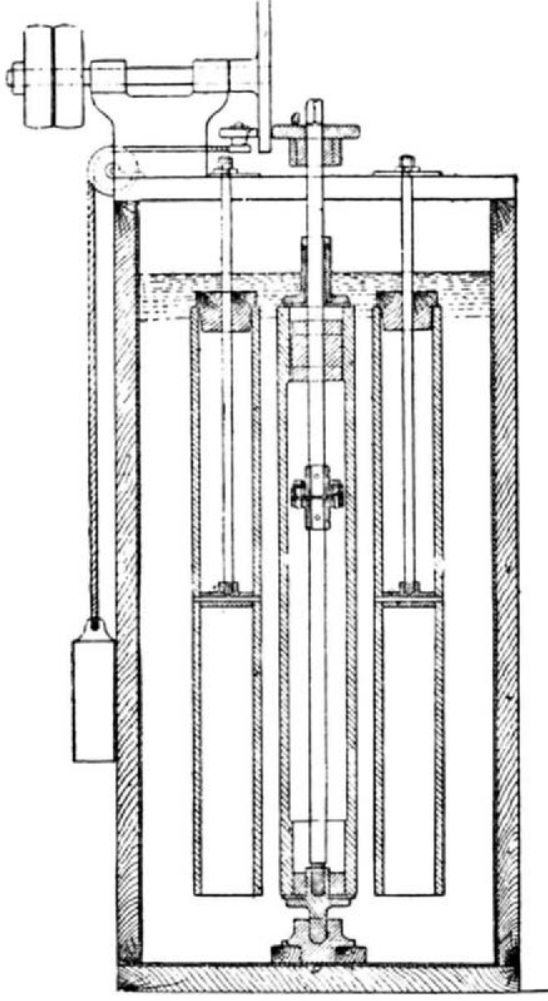

ILLUSTRATION I.-WILDE'S APPARATUS FOR COPPERING Calico Rollers.
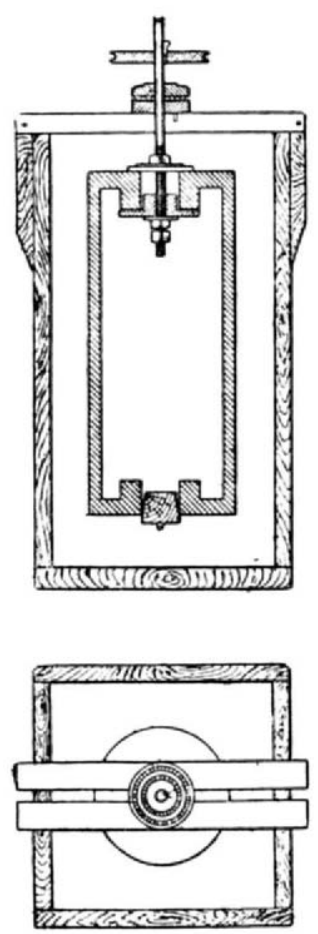

ILLUSTRATIONS 2 \& 3.-COTSWORTH'S APPARATUS FOR COPPERING Calico Roliters.

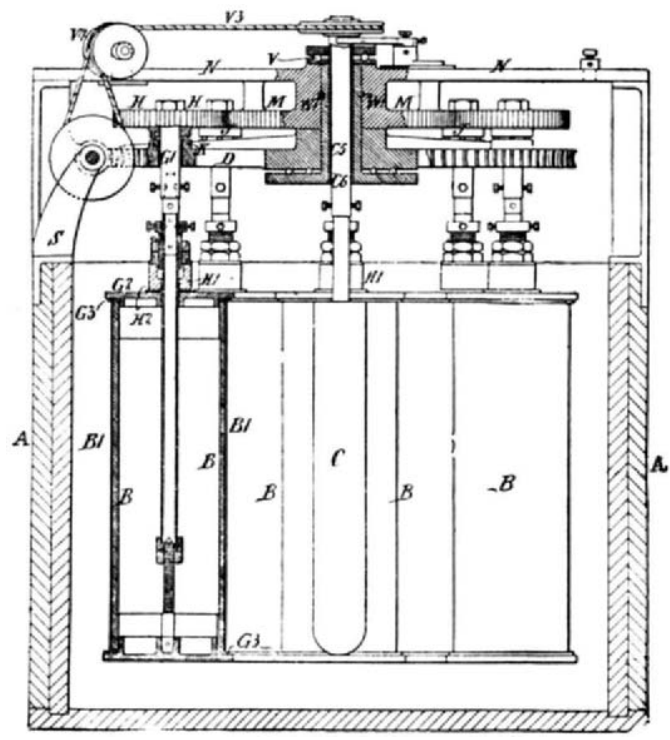

Illustration 4.-Wylie and Grant's Apparatus. 


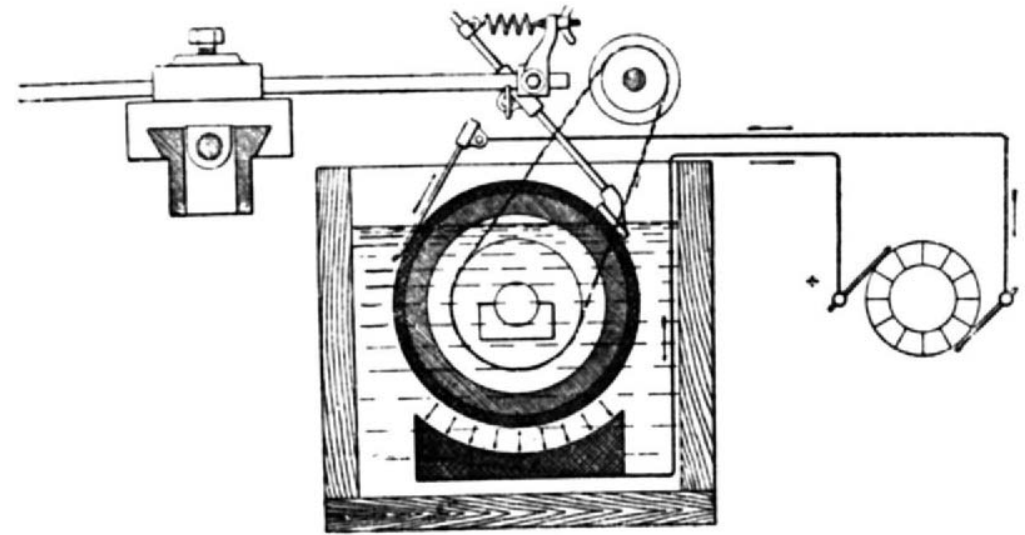

Illustration 5.-Elmore's PROCESS.

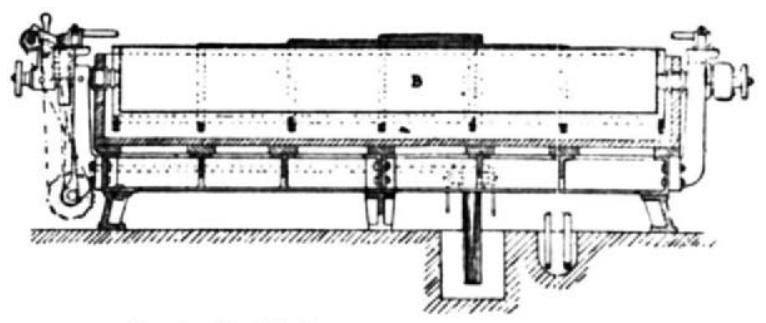

Longitudinal Scction.

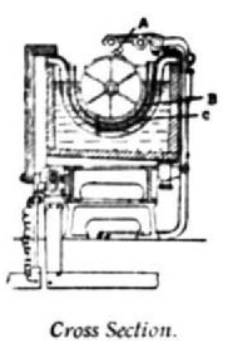

ILLUSTRATIONS 6 AND 7.-DUMOULIN's ApPaRATUS, TYPICAL OF THE Insulating Process.
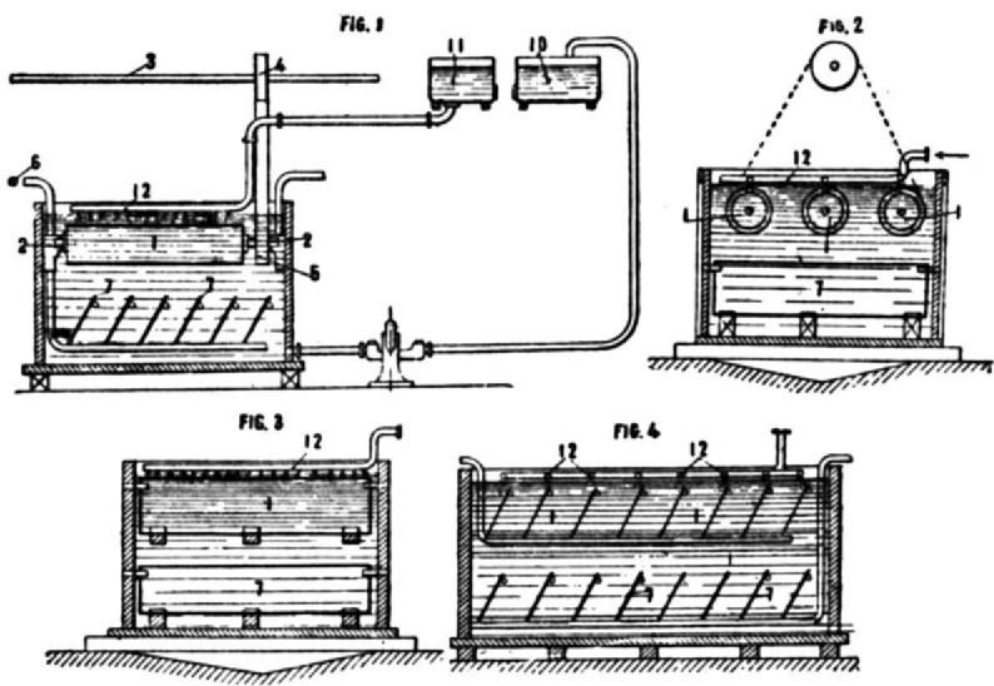

Illustration 8.-ThofehrN's Apparatus. 
acid per cubic foot $(28 \cdot 3 \mathrm{I} \mathrm{c}$. dcm.) of water, is used as electrolyte, and is stored in reservoirs placed at a height of from I to $2 \mathrm{ft}$. $\left(30^{\circ} 48 \mathrm{~cm}\right.$. to $60^{\circ} 96$ $\mathrm{cm}$.) above the electrolytic tanks ; thence it is conveyed to $\frac{3}{8} \mathrm{in} .\left(0^{\circ} 95 \mathrm{~cm}\right.$.) jets that deliver it in a stream upon the surface of the cathodes, which are placed at a distance of $I$ in. $(2 \cdot 54 \mathrm{~cm}$.) from the orifices of the jets. It is stated that a current of 300 amperes per square foot (9*29 sq. decim.) may be employed with safety at all points within the sphere of influence of the jets ; beyond this area it is obvious that the deposit would be pulverulent and useless. The radius of the protected area was found to be 5 in. $(127 \mathrm{~cm}$.), so the number and disposition of jets employed must be arranged accordingly.

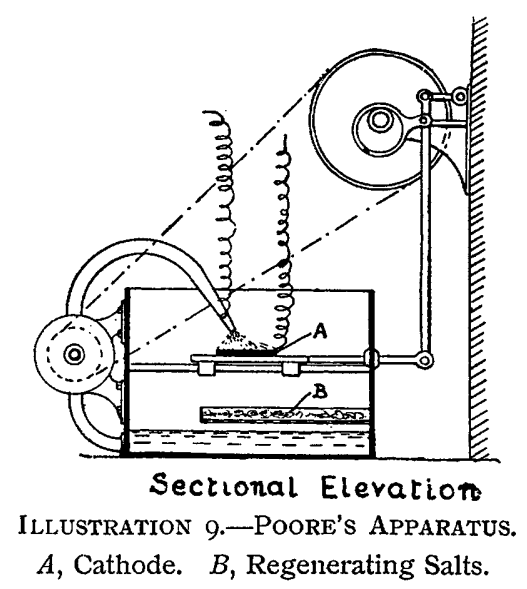

Poore in 1896 obtained a patent for an apparatus for depositing metals, as shown in Illustration 9. The solution is sprayed, or otherwise delivered, over the cathode plate, A, which may be an electrotype, and thus the stream or jet forms the only connection between the anode and the cathode. The cathode may be agitated by the table (upon which it is mounted) being moved to and

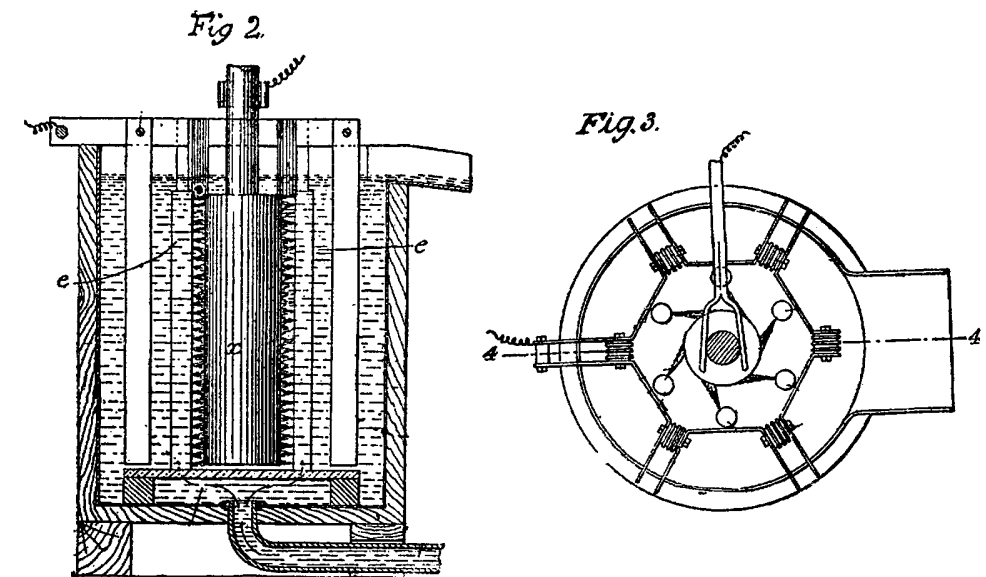

Section on 4-4, Fig. 3,

Illustration IO.--HaRRISON'S PROCESS.

$a$, Anode ; $d$, Cathode connection ; $e$, Perforated Pipes ; $x$, Revolving Cathode. VOL. I-T9 
fro by the eccentric arrangement shown in the illustration. On the tray $\mathrm{B}$ is placed the required salt to bring the electrolyte up to strength for re-use.

Dessolle worked for many years in Paris a process, which was patented in England in the year 1899, for coppering ornamental iron-work and statuary, in which the solution is caused to impinge against the object to be coppered, to remove the gas bubbles from under-cut portions.

The latest impingement process is Harrison's process, the details of which will be readily understood by reference to Illustration Io. Fig. 2 is a sectional elevation of the depositing cell, and Fig. 3 plan of the depositing cell.

The rapid deposition of copper by impingement of the electrolyte is not likely to be applied commercially until the amount of solution required to be circulated per square foot of cathode can be greatly reduced. With a current density of Ioo amperes per square foot ( $9^{\circ} 29 \mathrm{sq}$. dcm.) it is necessary by the ordinary impingement process to circulate about to gallons ( 45 litres) per minute per square foot of cathode surface, and unless the jets are continuous and the cathodes revolved a rough deposit is obtained. To obtain smooth deposits of copper by an impingement process it is essential that the solution be free from air, otherwise the deposit of copper is rough, and is deposited in the form of annular rings, as shown in Illustration II, which is a photograph of a lead plate coated with copper by an impingement process at a current density of $\mathrm{I} 60$ amperes per square foot $\left(9^{\cdot 28} \mathrm{sq} . \mathrm{dcm}\right.$.), temperature $50^{\circ} \mathrm{C}$., the electrolyte being forced at a pressure of a few pounds through a lead box bored with $\frac{1}{8}$-in. $\left(0^{\circ} 3 \mathrm{I} \mathrm{cm}\right.$.) holes at a distance of $\mathrm{I}$ in. $(2 \cdot 54 \mathrm{~cm}$.) apart from centre to centre.

Class 5.-Revolving Mandrel at a Critical Speed (Centrifugal PROCEss).- The author when carrying out experiments on the electrolytic production of copper tubes, which should be free from laminations, observed that if the mandrel constituting the cathode was revolved at a certain circumferential speed, smooth thick deposits of copper could be obtained at very high current densities which could not be obtained by any other method. Further investigations were made to determine this speed, and Illustration I2 shows the effect of increasing speed, every other condition being constant. The method eventually adopted for determining the critical speed required under varying conditions was to use a cathode in the form of a cone, as shown in Illustration $\mathrm{x}_{3}$, by which means the critical speed could be determined very readily. It has been found that the tensile strength of the copper increases with the speed of rotation.

Illustration I4 shows three typical copper deposits obtained on revolving mandrels before the critical speed is obtained.

It is found that very pure copper is obtained by the centrifugal process, even when very high current densities are employed, and the solution contains much foreign matter in suspension, as shown by the following analysis of a copper sheet :-

\begin{tabular}{|c|c|c|c|c|c|c|c|c|}
\hline Iron $\ldots$ & $\cdots$ & $\cdots$ & $\cdots$ & ... & $\cdots$ & ... & $\ldots$ & $\begin{array}{l}\text { Percentage. } \\
\text { 0.0189 }\end{array}$ \\
\hline Arsenic & ... & $\ldots$ & $\ldots$ & $\ldots$ & $\ldots$ & $\ldots$ & $\ldots$ & $0.00 \times 5$ \\
\hline Lead ... & ... & $\ldots$ & $\ldots$ & $\ldots$ & $\ldots$ & ... & $\ldots$ & 0.0013 \\
\hline Antimony & $\ldots$ & $\ldots$ & $\ldots$ & $\ldots$ & $\ldots$ & $\ldots$ & $\ldots$ & 0.0010 \\
\hline Bismuth & $\ldots$ & $\ldots$ & $\ldots$ & $\ldots$ & $\ldots$ & $\ldots$ & $\ldots$ & 0.0008 \\
\hline Silver ... & $\ldots$ & $\ldots$ & $\ldots$ & $\ldots$ & $\ldots$ & $\ldots$ & $\ldots$ & Absent \\
\hline Nickel & $\ldots$ & $\ldots$ & $\ldots$ & $\ldots$ & $\ldots$ & $\ldots$ & $\ldots$ & Absent \\
\hline Sulphur & ... & $\ldots$ & $\ldots$ & $\ldots$ & $\ldots$ & $\ldots$ & $\ldots$ & Absent \\
\hline Copper, by & liffe & & $\ldots$ & $\ldots$ & $\ldots$ & $\ldots$ & $\ldots$ & $99^{\circ} 9765$ \\
\hline
\end{tabular}




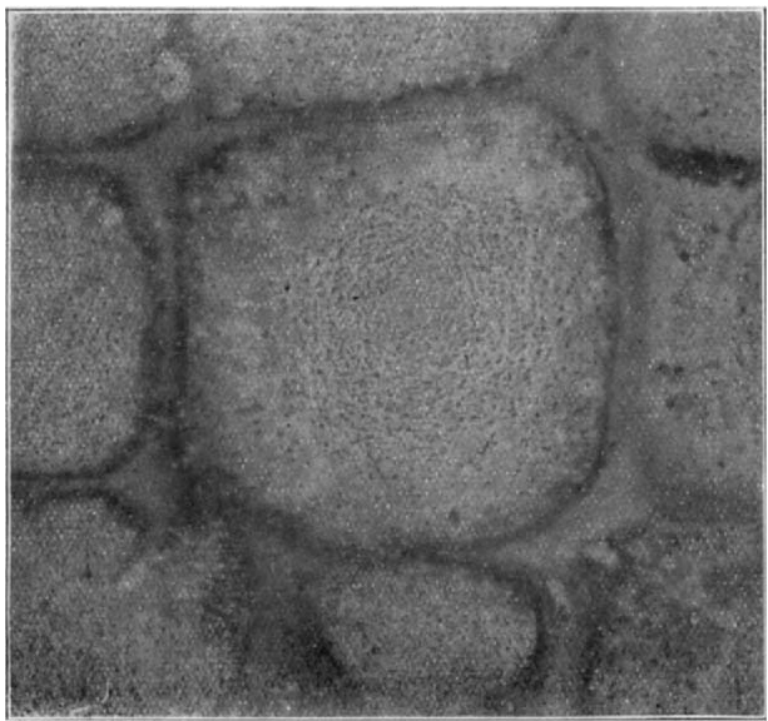

Illestration II,-Showing Lines PROduced by IMPINGING Jets 


\section{ILLUSTRATION 12.}

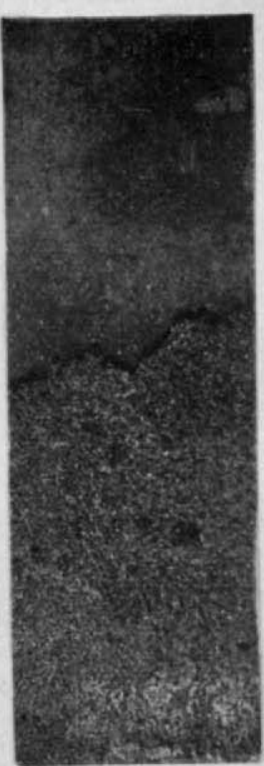

STATIONARY

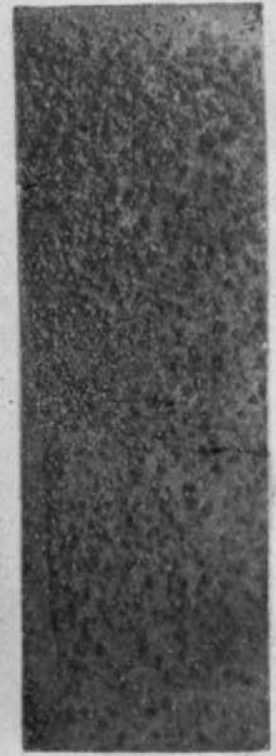

500 REVS.

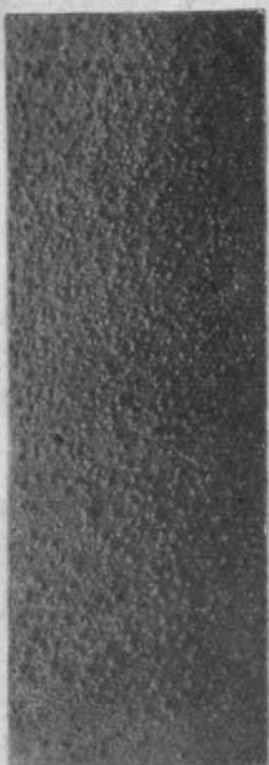

50 REVS.

100 REVS.
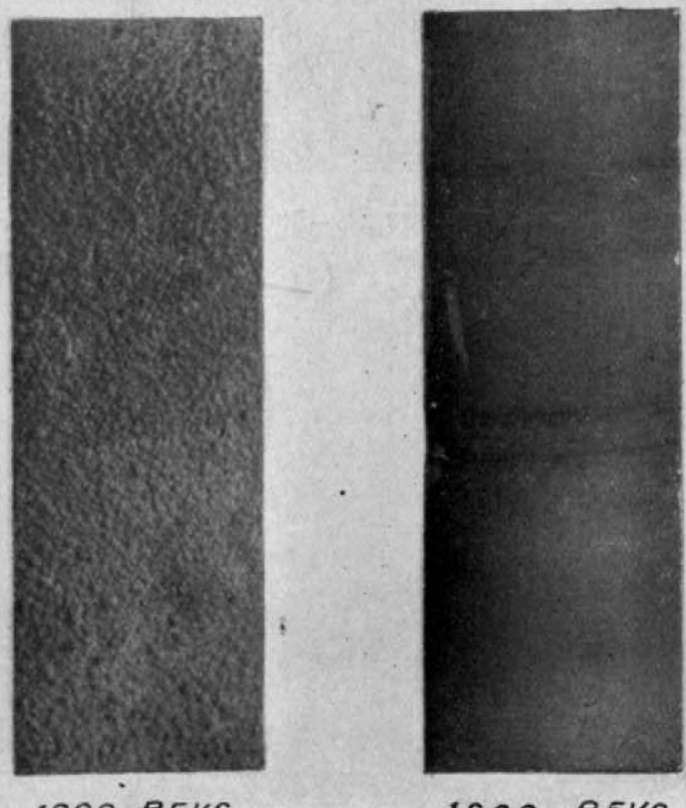

1800 REVS. 


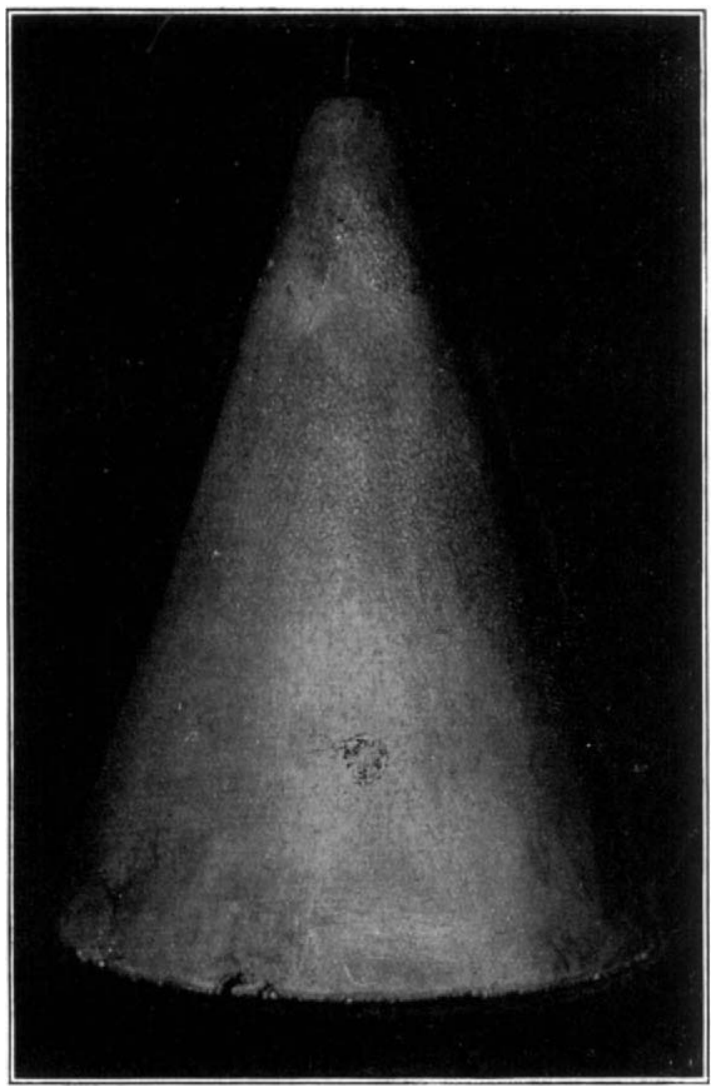

ILLC'STRATION 13.

CONE ILI. STRATING METHOD) OF DETERMINING CRITICIL SPEEAS. 


\section{ILLUSTRATION 14}

FIG 1 .

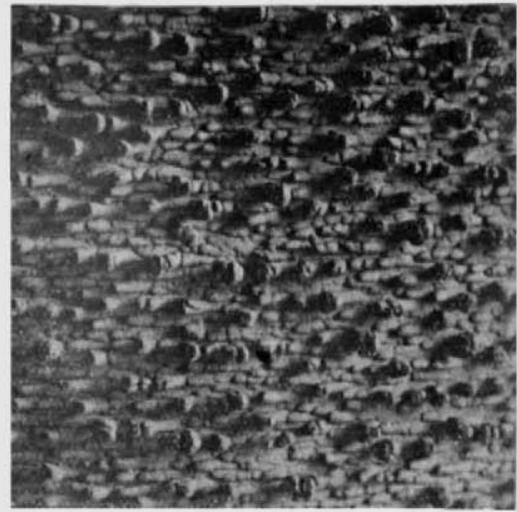

$F / G 2$.

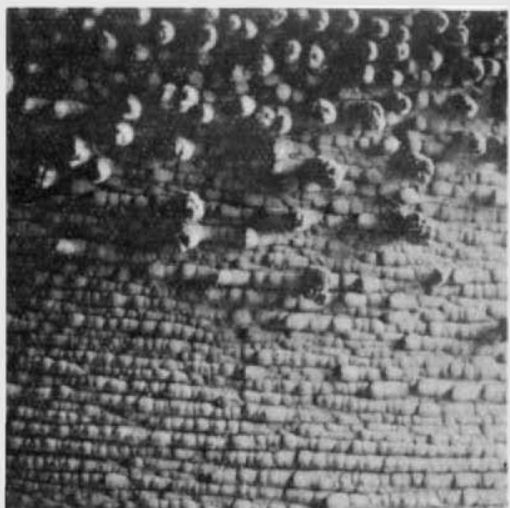

F/G. 3 .

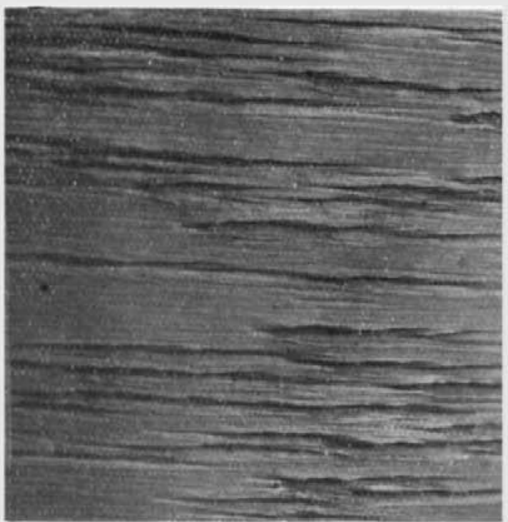

ILLUSTRATION I5

FIG 1 .

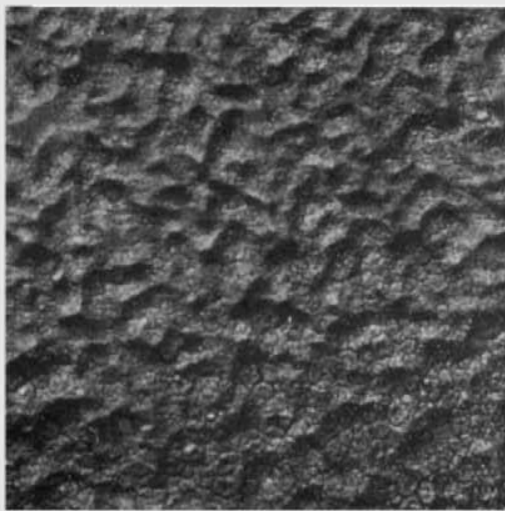

$F I G 2$.

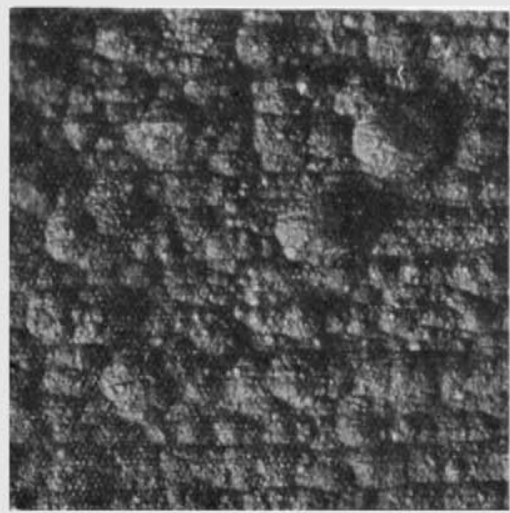


ILLUSTRATION I6.

Revolving Cathodes at Varying Speens.

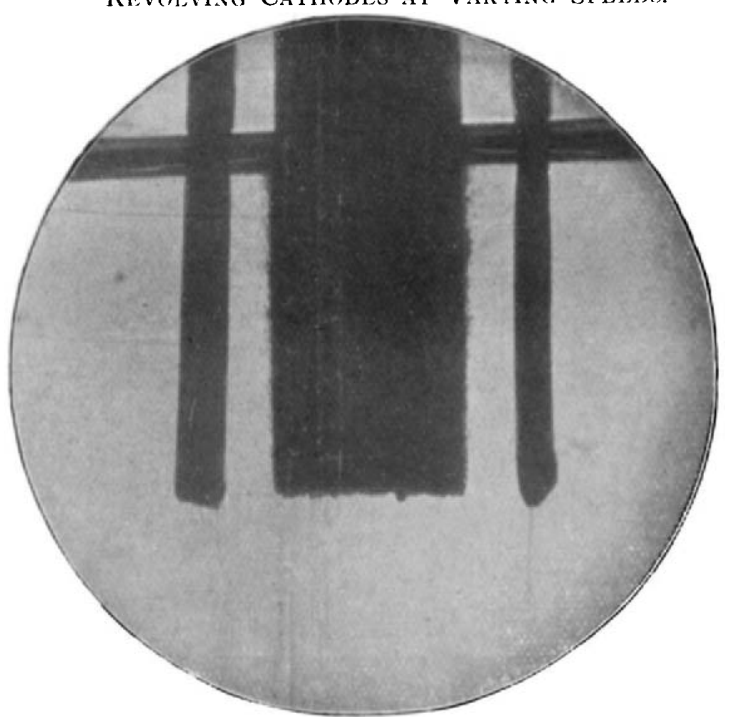

Fig. I.-STATIONARY.

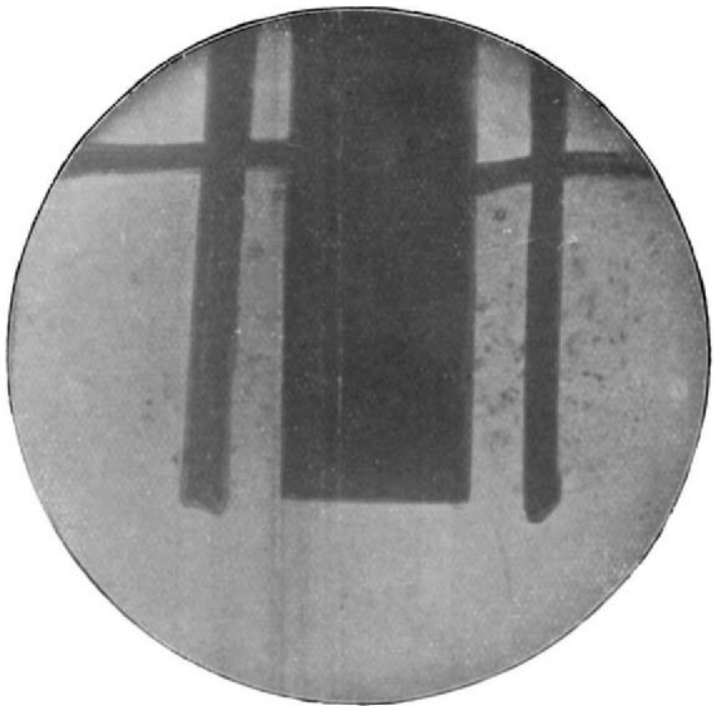

Fig. II.--Two SEcoNDS AFTER START.

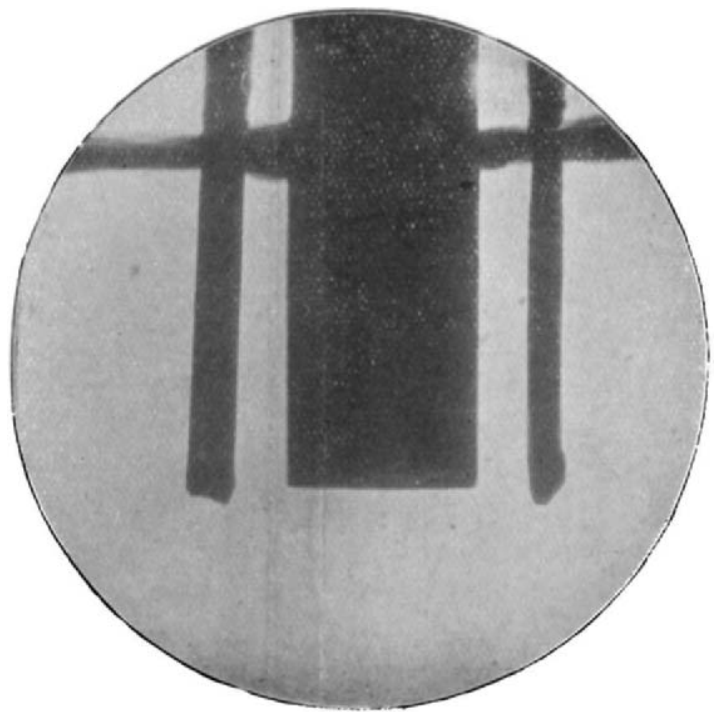

Fig. III.-CRITICAI SPEED. 
ILLUSTRATION I7.

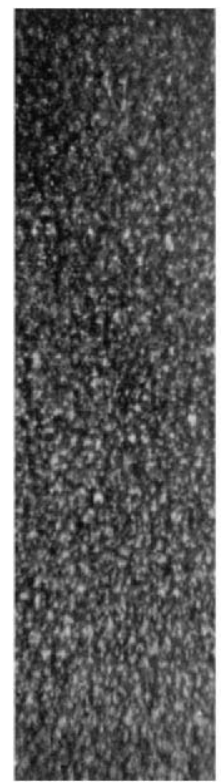

A.

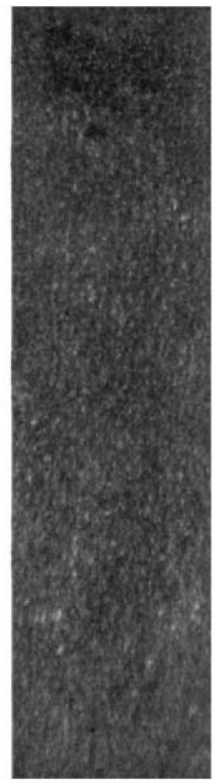

B.

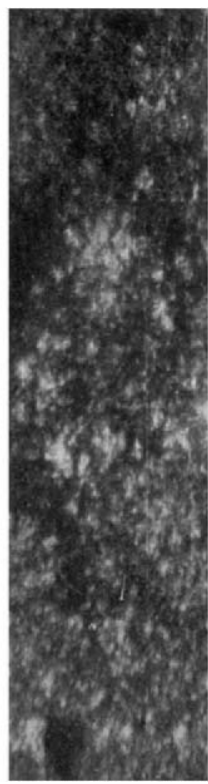

C. 7O DIAMETERS. MICROPHOTOGRAPHS OF COPPER DEPOSITED BY THE Centrifugal Process.
ILLUSTRATION I8.

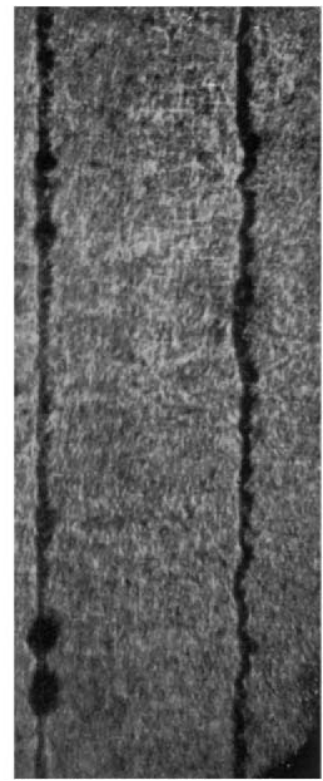

Fissure due to stopping of Mandrel.

SEction at Right ANG ,ES TO Surface of SheE 7 O Diameters. 


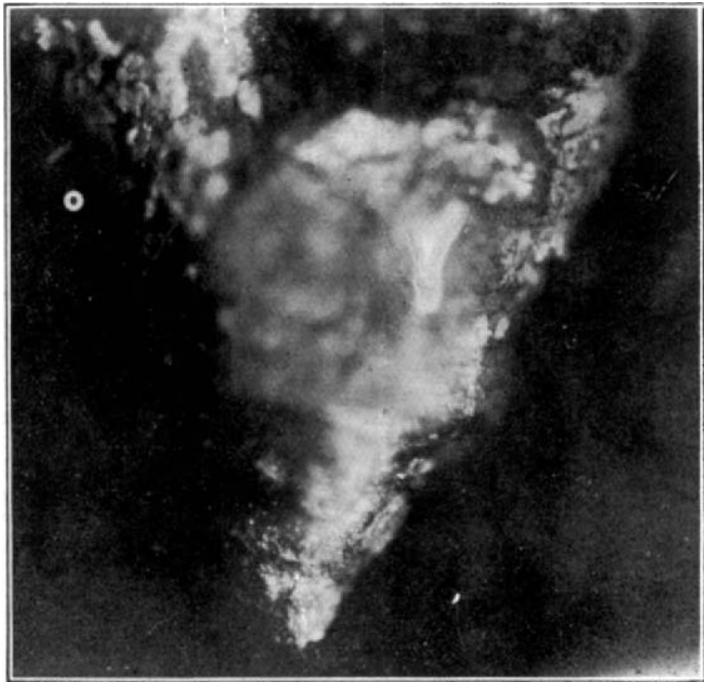

Illustration 19.-Root of Nodule Drawn from Copper Sheet.

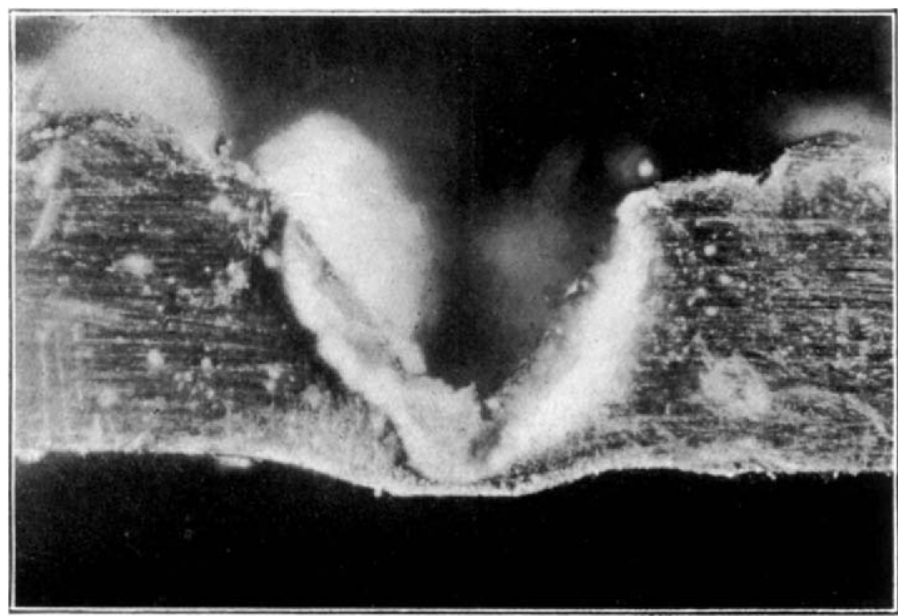

Iliustration 20.-Section of Copper Sheet Showing Cavity Left After Withdrawal, of Nodule. 


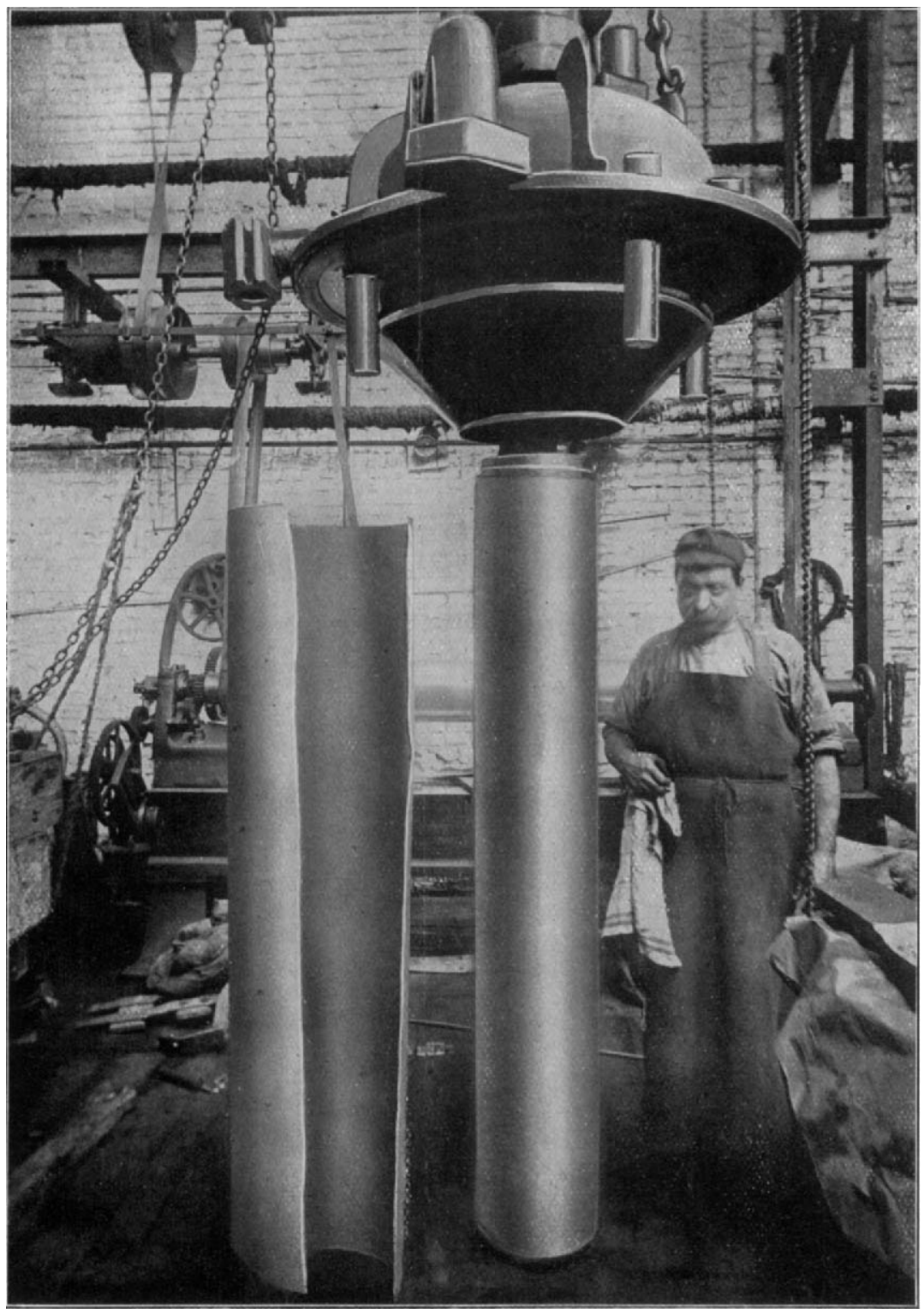

Illugtration 22.--Centrifugal. Process.

Tule Manidrel. 
The composition of the electrolyte usually employed is copper sulphate ro per cent., sulphuric acid to per cent., water 80 per cent.

In the ordinary process of copper refining, when a current density of about I7 amperes per square foot is employed, the copper is deposited in the form shown in Illustration 15, Fig. 2, the reverse side of the cathode which becomes anode in the series process is shown in Fig. I. The top of the nodules or excrescences form ledges on which the impurities in suspension settle and become ultimately sealed by the further deposition of copper, the circulation of the electrolyte not being sufficient to sweep them away; this difficulty is overcome in the centrifugal process as shown in Illustration $I 6$, which is a reproduction of photographs of a revolving cathode and two anodes thrown on a screen. Fig. I shows the mandrel stationary, Fig. 2 the mandrel immediately after starting to revolve; the air bubbles which were adhering to the mandrel can be seen being dissipated. Fig. 3

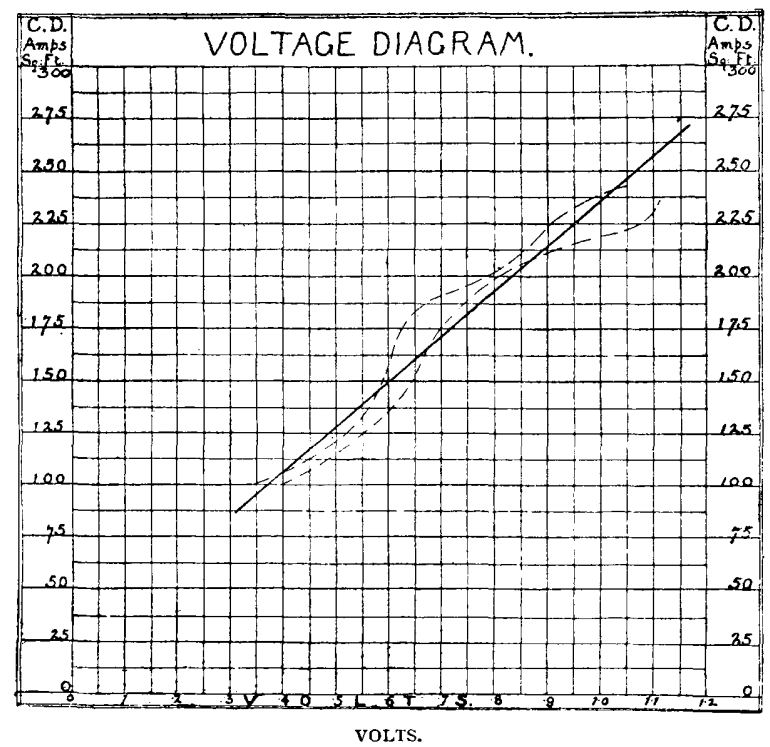

ILLUSTRATION 2 I.

shows the mandrel running under normal conditions at critical speed. By watching the process in operation on a screen it will be observed when any particles of impure metal detach themselves from the anodes and gradually approach the cathode, as soon as they arrive within a certain zone of the cathode they are immediately repelled by the centrifugal action.

Another great advantage of the centrifugal process is that the copper is free from lamination, such as is found when copper is burnished at stated intervals; this point has been established both by mechanical tests and microscopical examination. In the latter case specimens were cut from three samples (Illustration I7 A, B, and C), and were polished, etched, and photographed; in all cases the metal was close and homogeneous, and free from gaps, pits, and fissures.

It has been found that any stoppage or great variation in the speed of the mandrel causes lamination. This point is clearly shown in the microphotograph Illustration I8. The nodules or excrescences that form on copper are nearly always due to a particle of dirt settling on the cathode or 
a bubble of gas adhering tenaciously, with the result that the copper builds up around the adhering substance, rapidly increasing in size, as shown in the microphotograph Illustration 19 and 20.

Illustration $2 \mathrm{r}$ shows curves of the actual voltage employed for varying current densities, and Illustrations 22 and 23 the apparatus employed for the centrifugal process, the mandrel being provided with Pelton wheels, which are driven by the electrolyte impinging against them; Illustration 24 shows the method of expanding off the tubes by passing over the surface a rounded roller.

Copper tubes produced by this process without any drawing have been given a maximum stress of $x_{7}$ tons, and a tube after drawing has stood a pressure of 3,000 lbs. per square inch-thickness of metal 0.063 inch-without showing any signs of distress; and sheets, without rolling, have been given a maximum stress of from 28 to 34 tons $(2,000 \mathrm{lbs}$.) per square inch.

The production of copper wire by electrolytic means is a more difficult problem than the production of copper tubes and sheets. Various processes have been suggested and tried from time to time, such as electro-depositing copper on a thin copper wire until it has attained a considerable thickness,
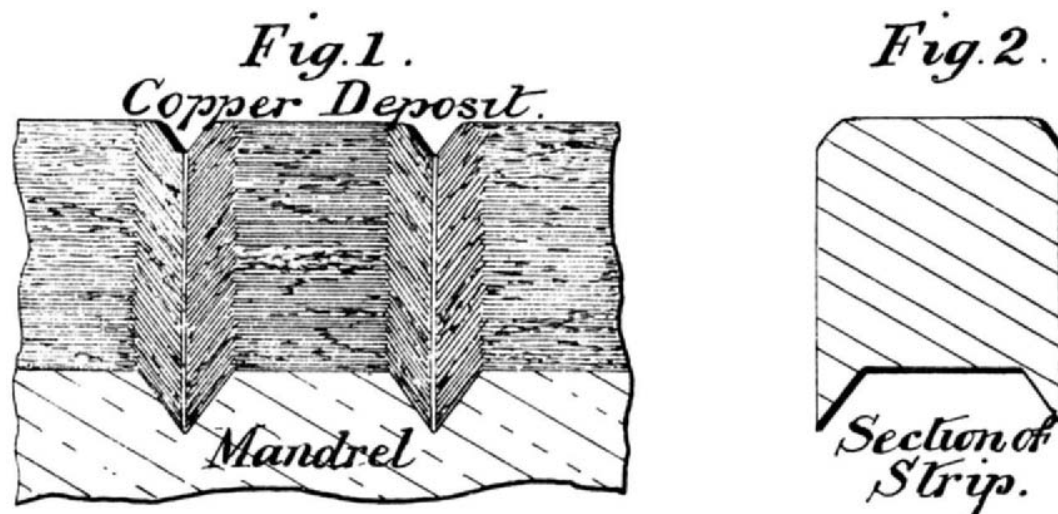

ILlustration 25.

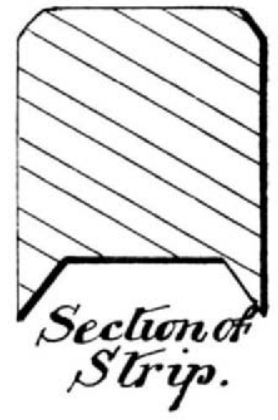

and then drawing the thickened wire down again to a comparatively fine wire. Swan and Sanders have both experimented with such processes, but so far they have not been worked commercially. Elmore's process consists in producing copper tubes by his burnishing process and cutting them up in long spirals. Such a process is very costly, and the wire when finished and subjected to a torsional test is very unsatisfactory. Other experimenters have tried placing insulating strips on a cylindrical mandrel so as to produce long copper spirals; the spirals thus produced are uneven and unsuitable for drawing down to wire on account of the roughnesses formed on the edges. The method employed in conjunction with the centrifugal process consists in making on the mandrel a spiral scratch. The effect of this scratch, which must be angular, is to affect the molecular structure of the copper and to form a cleavage plane, as shown in Illustration 25; if the scratch is not angular but round at the base the copper will not divide. The line of cleavage is no doubt formed in the same way as a cast metal, as shown in Illustration 26, Fig. I being a sample of antimony sulphide and Fig. 2 a sample of zinc, both cast in a rectangular mould. In each case the line of cleavage can be clearly seen; if the mould has rounded corners the crystal- 


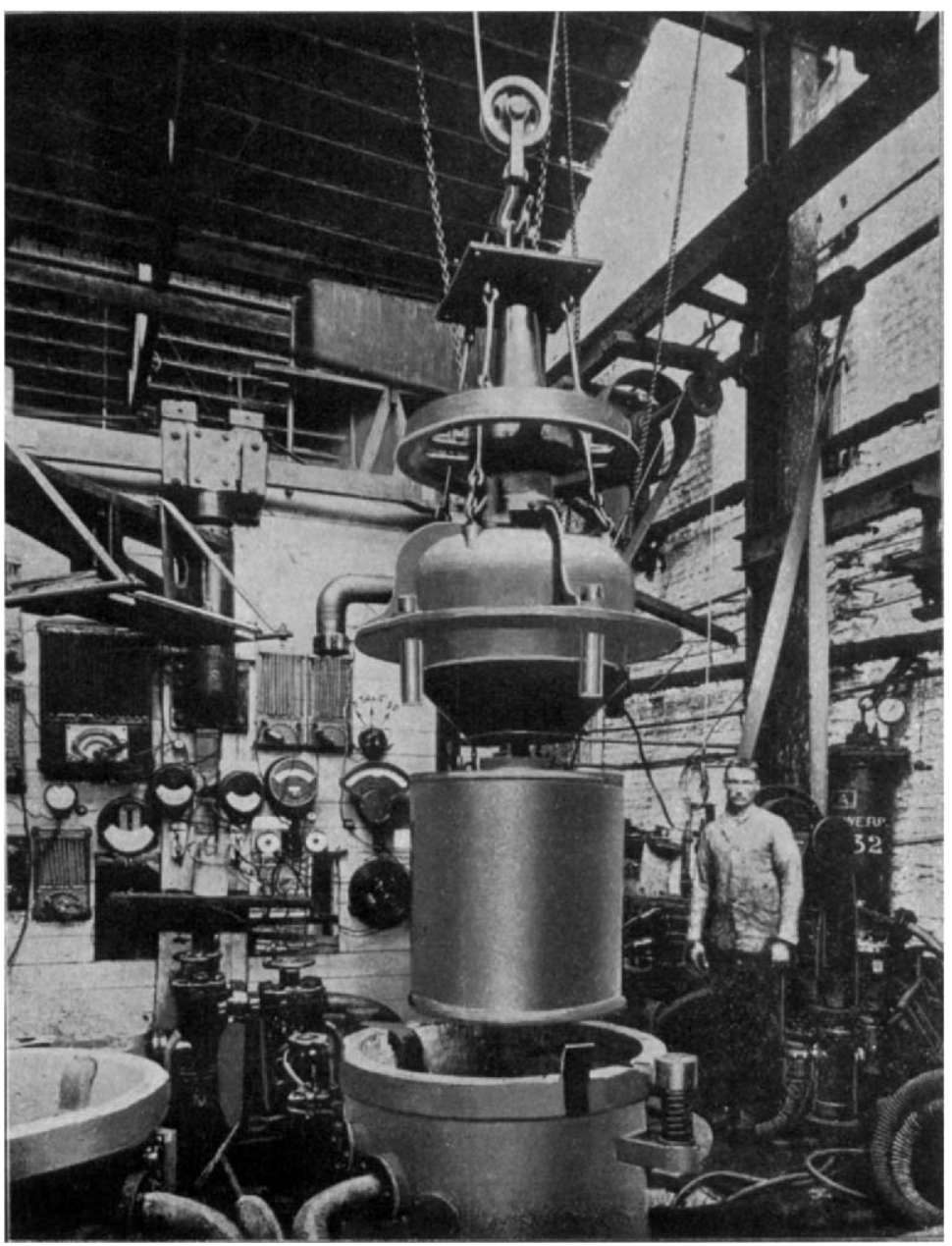

Illustration 23-Centrifggal Process. SHEET MANDREL. 


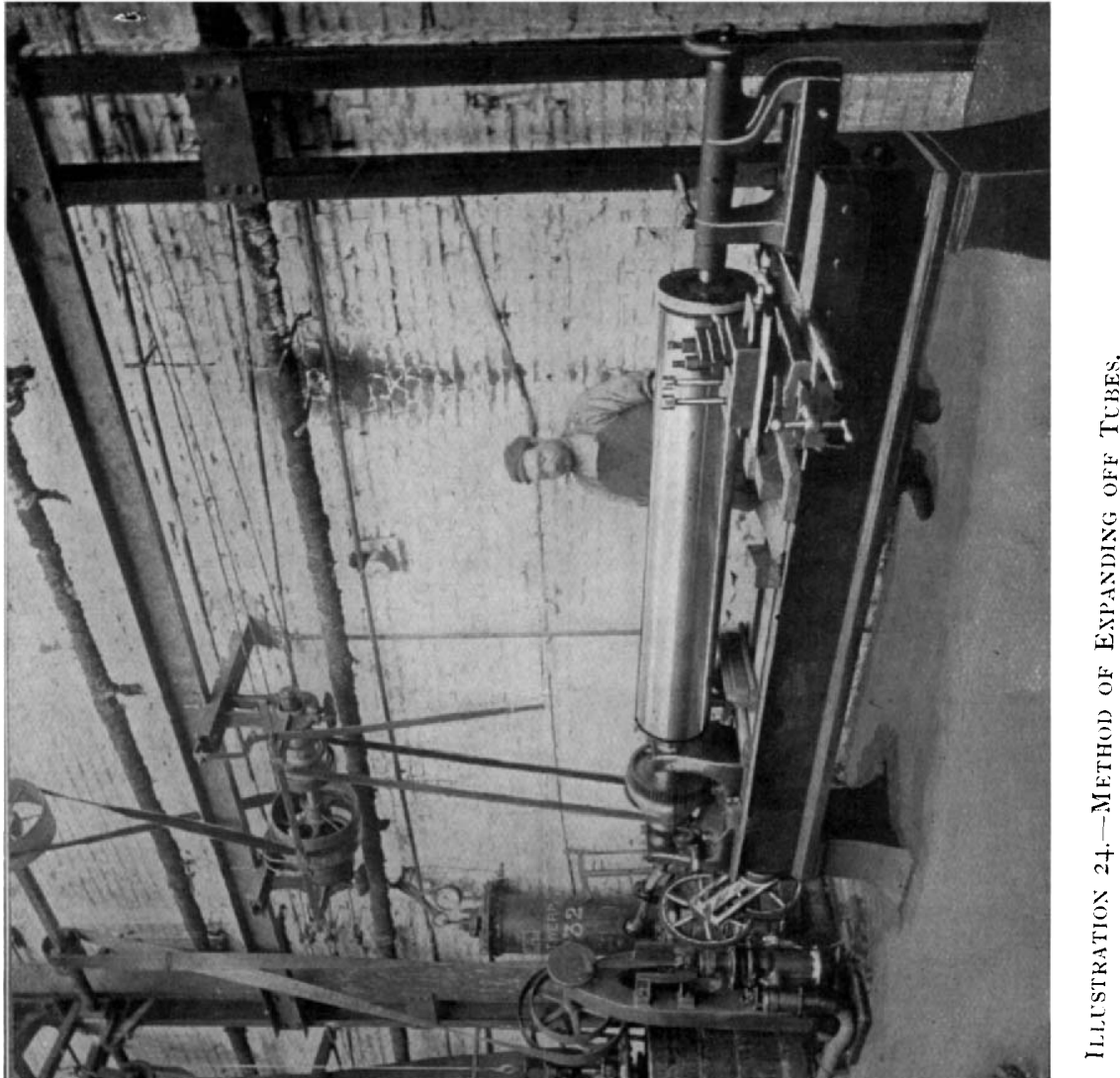




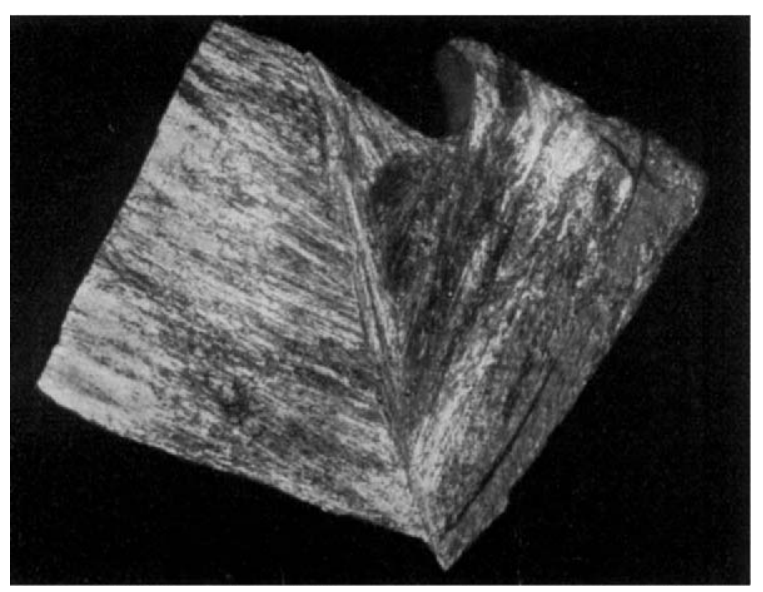

FIG. I.

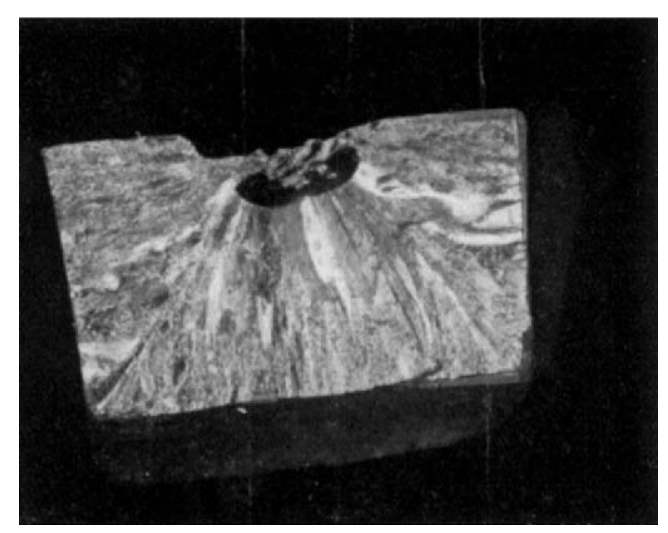

FII 2.2.

ILLCETRATION 26. 


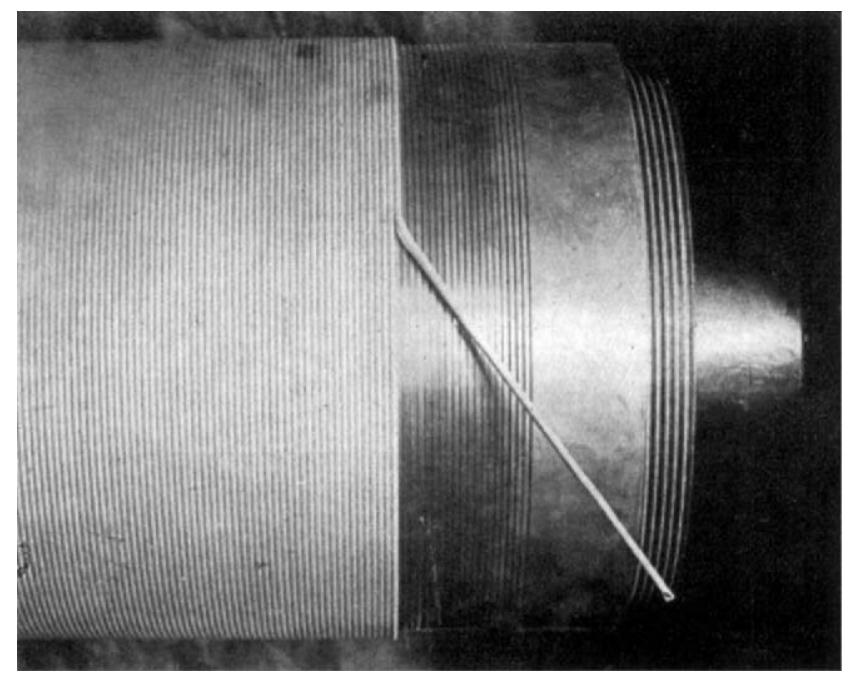

ILIUSTRATION 27 . 
lisation would be radial, and there would be no cleavage plane. The crystalline structure of the deposited copper has a line of cleavage starting with the sharp point of the scratch on the mandrel. The copper separates more readily if unwound at an angle to the axis of the mandrel, as shown in Illustration 27. The construction of mandrel capable of making three or four miles of wire in one operation in a few hours from crude copper is shown in Illustration 28. The vat is annular in construction, the mandrel being $7 \mathrm{ft}$. in diameter and making about fifty revolutions per minute. A great feature

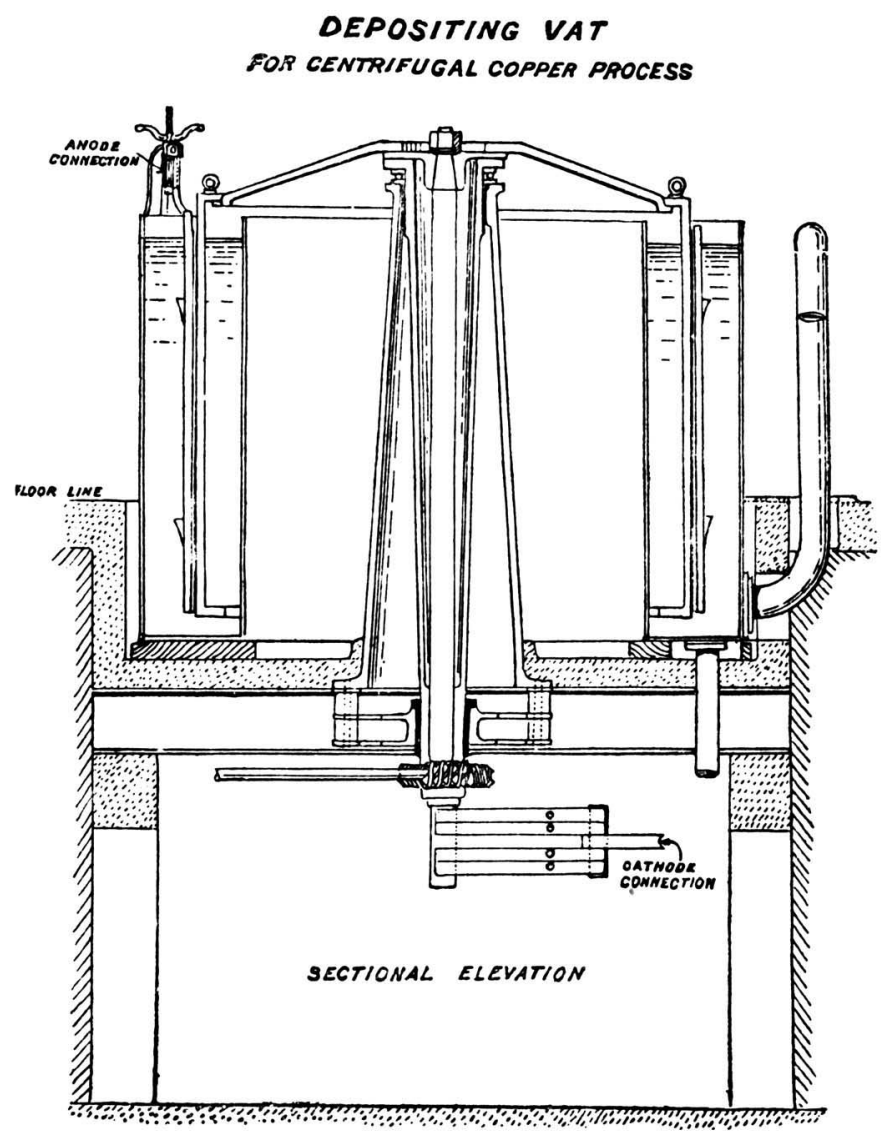

ILLUSTRATION 28.

of such a vat is that there are no working parts in the electrolyte and no stuffing boxes or glands.

The capital expenditure on plant required for the centrifugal process compares very favourably with an up-to-date rolling mill and wire drawing plant; the cost of such a plant with buildings, engines, and the necessary plant is about $£ 80,000$ for an output of about roo tons per week or 5,000 tons per annum. 


\section{ESTIMATE OF COST OF WORKING PROCESS.}

\section{Estimated Cost of Plant for Producing ro,oco Tons of Tubes, Sheets} and Wire per Annum by the Centrifugal Process.

Cost of 95 vats and accessories $\quad \ldots$

$\begin{array}{llll}\text { Machinery for finishing tubes, sheets and wire } & \ldots & \ldots & 5,000\end{array}$

$\begin{array}{lllllll}\text { Cranes and lifting gear } \ldots & \ldots & \ldots & \ldots & \ldots & \ldots & 1,500\end{array}$

$\begin{array}{lllllllll}\text { Building } \ldots & \ldots & \ldots & \ldots & \ldots & \ldots & \ldots & \ldots & 15,000\end{array}$

$\begin{array}{lllllll}\text { Plant for mandrel-making } & \ldots & \ldots & \ldots & \ldots & \ldots & \mathbf{2}, 000\end{array}$

$\begin{array}{lllllll}\text { Machinery for fitting shop } & \ldots & \ldots & \ldots & \ldots & \ldots & \text { I,500 }\end{array}$

$\begin{array}{llllll}\text { Pumps, atomisers, filter tanks } \ldots & \ldots & \ldots & \ldots & \ldots & 5,000\end{array}$

$\begin{array}{llllllllll}\text { Foundry } & \ldots & \ldots & \ldots & \ldots & \ldots & \ldots & \ldots & \ldots & 2,500\end{array}$

$\begin{array}{lllllll}\text { Driving machinery for vats } & \ldots & \ldots & \ldots & \ldots & \ldots & 5,000\end{array}$

$\begin{array}{lllllll}\text { Conductors and electrolyte } & \ldots & \ldots & \ldots & \ldots & \ldots & 5,000\end{array}$

$\begin{array}{lllllll}\text { Floating capital for copper } & \ldots & \ldots & \ldots & \ldots & \ldots & £ 106,500 \\ \end{array}$

30,000

$£ \mathbf{3} 6,500$

\section{ESTIMATE OF COST OF PRODUCING COPPER TUBES, SHEET AND WIRE BY THE CENTRIFUGAL PROCESS DIRECT FROM CRUDE COPPER.}

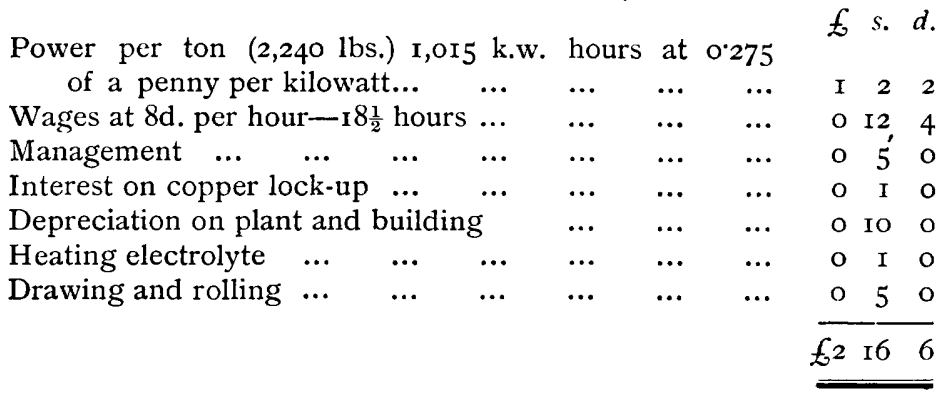

These figures represent the actual working cost, on which there would be a further reduction for the precious metals recovered, and if $f_{\mathrm{I}}$ ros. be deducted from the above cost, which is at present the difference between Chili-bar and electrolytic copper, the cost per ton is reduced to $18 \mathrm{~s} .5 \mathrm{~d}$.

Advantages Claimed for the Centrifugal Process.-The following are some of the chief advantages claimed for the process: The copper is refined and manufactured into sheets or tubes in one operation, the copper being of a hard nature, similar to that which is cold-rolled; the process is at least ten times faster than any existing electrolytic process; a high current can be employed without deteriorating the quality of the copper; there is no risk of lamination, as no burnisher is employed ; the plant is simple and free from mechanical complications, the amount of copper locked up for a given output is small compared to other processes; finally, anodes of very impure copper can be used as compared to the anode copper used in other systems.

CoNCLUSION.- In conclusion, I should like to acknowledge my indebtedness to those who have worked so hard and with so much enthusiasm during the years it has taken to develop the centrifugal process. The work at times has been of a most arduous character, and to obtain the data required it has been necessary to run the plant continuously day and night for long periods. 